\section{BMJ Open Respiratory Research}

\title{
Classification of aerosol-generating procedures: a rapid systematic review
}

Tanya Jackson (D) ,' Danika Deibert, ${ }^{1}$ Graeme Wyatt, ${ }^{1}$ Quentin Durand-Moreau, ${ }^{1}$ Anil Adisesh (1D) , ${ }^{2}$ Kamlesh Khunti, ${ }^{3}$ Sachin Khunti, ${ }^{4}$ Simon Smith, ${ }^{5}$ Xin Hui S Chan (D) , ${ }^{6}$ Lawrence Ross, ${ }^{7}$ Nia Roberts, ${ }^{8}$ Elaine Toomey, ${ }^{9}$ Trisha Greenhalgh, ${ }^{10}$ Isheeta Arora, ${ }^{11}$ Susannah M Black, ${ }^{11}$ Jonathan Drake, ${ }^{11}$ Nandana Syam, ${ }^{11}$ Robert Temple, ${ }^{11}$ Sebastian Straube (i) ${ }^{1}$

\section{ABSTRACT}

In the context of covid-19, aerosol generating procedures have been highlighted as requiring a higher grade of personal protective equipment. We investigated how official guidance documents and academic publications have classified procedures in terms of whether or not they are aerosol-generating. We performed a rapid systematic review using preferred reporting items for systematic reviews and meta-analyses standards. Guidelines, policy documents and academic papers published in english or french offering guidance on aerosol-generating procedures were eligible. We systematically searched two medical databases (medline, cochrane central) and one public search engine (google) in march and april 2020. Data on how each procedure was classified by each source were extracted. We determined the level of agreement across different guidelines for each procedure group, in terms of its classification as aerosol generating, possibly aerosolgenerating, or nonaerosol-generating. 128 documents met our inclusion criteria; they contained 1248 mentions of procedures that we categorised into 39 procedure groups. Procedures classified as aerosol-generating or possibly aerosol-generating by $\geq 90 \%$ of documents included autopsy, surgery/postmortem procedures with high-speed devices, intubation and extubation procedures, bronchoscopy, sputum induction, manual ventilation, airway suctioning, cardiopulmonary resuscitation, tracheostomy and tracheostomy procedures, non-invasive ventilation, high-flow oxygen therapy, breaking closed ventilation systems, nebulised or aerosol therapy, and high frequency oscillatory ventilation. Disagreements existed between sources on some procedure groups, including oral and dental procedures, upper gastrointestinal endoscopy, thoracic surgery and procedures, and nasopharyngeal and oropharyngeal swabbing. There is sufficient evidence of agreement across different international guidelines to classify certain procedure groups as aerosol generating. However, some clinically relevant procedures received surprisingly little mention in our source documents. To reduce dissent on the remainder, we recommend that (a) clinicians define procedures more clearly and specifically, breaking them down into their constituent components where possible; (b) researchers undertake further studies of aerosolisation during these procedures; and (c) guideline-making and policy-making bodies address a wider range of procedures.

\section{INTRODUCTION}

Humans ordinarily expel particles from the mouth and nose while breathing, talking and coughing, as well as during certain healthcare procedures. These particles are formed of water and mucus that contain infectious material, including viruses. Exhaled particles may range in size between 0.01 and $1000 \mu \mathrm{m}$, depending on mechanism of generation and site of origin, with up to 308600 particles being produced per cough. ${ }^{2}$ Procedures (eg, intubation) can change the volume, size, distribution and speed of particles expelled as well as changing their origin from different parts of the respiratory tract.

Viruses lose viability at different rates, depending on the virus family and functional surface characteristics, droplet expulsion mode and stability, environment, and time. ${ }^{3-5}$ Susceptible persons in the vicinity of an infected individual can therefore become infected through multiple particle routes, including inhaling close to the source or touching and transferring particles that have landed on surfaces. Expelled particles can spread widely in a room in a short time after a cough, ${ }^{6-8}$ and cases are recorded where infectious material has dispersed through ventilation systems or windows. ${ }^{9}$ Infectious particles may also be dispersed by other routes such as toilet flushing or doffing protective clothing. ${ }^{1011}$

Infection control practices have traditionally classified disease transmission as occurring through 'contact' (implying direct physical transfer), 'droplet' or 'airborne' routes. ${ }^{12}$ Larger particles settle in a reasonably short distance, and are referred to as 'droplets' in the infection control context. Smaller particles can travel as aerosols on air currents, remaining in the air for longer and distributing over a wide area. ${ }^{13}$ 
Severe acute respiratory syndrome coronavirus 2 (SARS-CoV-2), the virus that causes coronavirus disease 2019 (COVID-19) can be transmitted via aerosols. ${ }^{14}$ Therefore, medical procedures that generate aerosols can lead to transmission of the virus to personnel performing the procedures as well as to bystanders. For that reason, physicians and other healthcare providers are understandably concerned about aerosol-generating procedures, infection risk and the need for appropriate personal protective equipment. ${ }^{1516}$

Infection control practices include wearing an appropriate ensemble of personal protective equipment as well as using proper procedures for donning and doffing. The critical items of personal protective equipment in relation to aerosolised infectious matter are respiratory protective devices, specifically filtering facepiece respirators such as FFP2, FFP3 or N95 type masks. These should be used together with other items as appropriate, such as gloves, gowns, shoe covers and eye protection equipment. Furthermore, personal protective equipment should be applied together with other hazard control measures in the hierarchy of controls, such as cohorting COVID-19 positive patients, surface cleaning and ensuring adequate air ventilation. ${ }^{17} 18$

The WHO and other authorities recommend the use of respirators when performing aerosol-generating procedures on patients with known or suspected COVID19, but deem standard surgical masks (which do not seal to the face and are not considered respirators) adequate for routine care not involving aerosol-generating procedures. ${ }^{12}$ The question of what is or is not an aerosolgenerating procedure is therefore of considerable importance in the COVID-19 context, especially when certain items of personal protective equipment, such as filtering facepiece respirators, are in short supply.

Our specific research question was: how have official guidance documents and academic publications classified procedures in terms of whether or not they are aerosol-generating?

\section{METHODS}

We conducted a rapid systematic review in line with the Cochrane Interim Guidance for Rapid Reviews. ${ }^{19}$ Our review was registered as a COVID-19 Rapid Evidence Review with the National Collaborating Centre for Methods and Tools at McMaster University (https://www. nccmt.ca/knowledge-repositories/covid-19-evidencereviews/7).

We have reported this review according to the Preferred Reporting Items for Systematic Reviews and MetaAnalyses reporting criteria for systematic reviews where appropriate (online appendix 1). ${ }^{20}$ Our review is part of a 'Programme of Research and Training in Occupational Medicine' by SSt's team at the University of Alberta. It is also one of a suite of reviews on personal protective equipment initially commenced as part of the Oxford COVID-19 evidence series and edited by TG.
We included documents in English or French (read fluently by the authors, reflecting Canada's bilingualism) and published since 1 January 2000 . We deemed eligible for inclusion peer-reviewed journal articles, pre-prints, conference proceedings and grey literature from a variety of sources such as healthcare organisations, agencies and government departments. To be included, documents had to report on procedures and state whether they are aerosol-generating, possibly aerosol-generating or not aerosol-generating.

Systematic literature searching was conducted from 26 March 2020 to 8 April 2020. We searched for relevant literature in Medline (1946 to present via OVID), in Cochrane Central (from inception to present) and in Google using English and French keywords, as well as performing searches on English and French websites. These search strategies are detailed in online appendix 2. We also considered documents previously known to the authors, or that were shared with us by others after we had made known our intention of writing the present systematic review.

A data extraction form was developed and piloted, and used to extract citation details, definitions of aerosolgenerating procedures used in the source documents and lists of procedures that were classified (as aerosolgenerating, possibly aerosol-generating or not aerosolgenerating). Extracted data for each source document were verified by a second researcher, and any discrepancies found in the verification stage were adjudicated by a third researcher. Quantitative data on procedures identified as aerosol-generating, possibly aerosol-generating or not aerosol-generating were then generated by giving procedures one count for each document in which they were thus classified.

Different source documents used slightly different terminology to describe procedures. We combined similar procedures into a total of 39 procedure groups based on author consensus, using an iterative process of categorising the records and creating groups until we felt that the existing groups sufficiently captured the data. The resulting procedure groups are shown in table 1 .

For aerosol-generating procedures, we developed groupings of likely aerosol sources using the same process, resulting in 12 aerosol source groups (table 2).

For each procedure group, we calculated the percentage of agreement among the contributing sources on how it was classified (aerosol-generating, possibly aerosol-generating, or not aerosol-generating). We considered $90 \%$ or greater agreement on a procedure group as aerosol-generating or possibly aerosolgenerating as very strong consensus, and $80 \%$ or greater agreement as strong consensus. Where there was a high level of disagreement between sources, or where a procedure was mentioned by only a few sources, we considered explanations. 


\begin{tabular}{|c|c|}
\hline 1 & Airway suctioning \\
\hline 2 & Autopsy \\
\hline 3 & $\begin{array}{l}\text { Breaking closed ventilation systems (intentionally or } \\
\text { unintentionally) }\end{array}$ \\
\hline 4 & Bronchoscopy \\
\hline 5 & Cardiopulmonary resuscitation \\
\hline 6 & Chest physiotherapy \\
\hline 7 & Colonoscopy \\
\hline 8 & Coughing \\
\hline 9 & ENT and neurosurgery \\
\hline 10 & Nitrous oxide (Entonox) administration \\
\hline 11 & Gl endoscopy (not further specified) \\
\hline 12 & Handling soiled laundry \\
\hline 13 & High-frequency oscillatory ventilation \\
\hline 14 & High-flow oxygen therapy \\
\hline 15 & $\begin{array}{l}\text { Intra/extra pulmonary high-frequency oscillation } \\
\text { devices }\end{array}$ \\
\hline 16 & Intubation and extubation procedures \\
\hline 17 & Labour and delivery \\
\hline 18 & Lung function testing \\
\hline 19 & Manipulation of masks \\
\hline 20 & Manual ventilation \\
\hline 21 & Mechanical ventilation \\
\hline 22 & Mechanical insufflation and exsufflation \\
\hline 23 & Nasogastric tube insertion \\
\hline 24 & Nasopharyngeal aspirate \\
\hline 25 & Nasopharyngeal and oropharyngeal swabbing \\
\hline 26 & Nasopharyngoscopy or laryngoscopy \\
\hline 27 & Nebulised or aerosol therapy \\
\hline 28 & Non-invasive ventilation \\
\hline 29 & Oral and dental procedures \\
\hline 30 & Prone positioning \\
\hline 31 & Sputum induction \\
\hline 32 & Suction of body fluids (not further specified) \\
\hline 33 & Supraglottic airways \\
\hline 34 & $\begin{array}{l}\text { Surgery/postmortem procedures with high-speed } \\
\text { devices }\end{array}$ \\
\hline 35 & Thoracic surgery and procedures \\
\hline 36 & Toilet use and flushing \\
\hline 37 & Tracheostomy and tracheostomy procedures \\
\hline 38 & Upper Gl endoscopy \\
\hline 39 & Vacuum cleaning \\
\hline
\end{tabular}

ENT, ear, nose and throat; GI, gastrointestinal.

\section{RESULTS}

\section{Description of dataset}

Our searches identified 162 potentially eligible documents of which 153 remained after elimination of

\begin{tabular}{ll}
\hline Table 2 & Aerosol source groups \\
\hline 1 & Autopsy \\
2 & Cleaning tasks \\
3 & Gastrointestinal (not further specified) \\
4 & Inhaled therapy \\
5 & Labour and delivery \\
6 & Oronasal \\
7 & Upper gastrointestinal \\
8 & Laboratory \\
9 & Lower gastrointestinal \\
10 & Patient care \\
\hline 11 & Tracheobronchial \\
\hline 12 & Wound/invasive procedure \\
\hline
\end{tabular}

duplicates. Of these, 25 documents were excluded because they did not meet the eligibility criteria, leaving 128 documents that were included in our rapid systematic review. Online appendix 3 lists the references of the included documents. Online appendix 4 details the excluded documents.

We used documents from nine countries including Canada $(\mathrm{n}=60)$, UK $(\mathrm{n}=9)$, France $(\mathrm{n}=8)$, USA $(\mathrm{n}=4)$, Australia $(n=2)$, Ireland $(n=2)$, Luxembourg $(n=2)$, China $(\mathrm{n}=1)$ and New Zealand $(\mathrm{n}=1)$, as well as two documents from European agencies and societies and six documents from the WHO. We did not assign a country of origin for academic journal publications. Our included documents comprised 91 documents in English and 37 documents in French. The documents were from academic journals $(n=31)$, supranational agencies $(e g$, the WHO) $(n=7)$, government agencies (including regional and federal health boards and departments dedicated to public health, infection prevention, seniors' health and longterm care, paediatric health and critical illness) $(n=72)$ and professional associations (respiratory therapists and physiotherapists predominating) $(\mathrm{n}=17)$. Most included documents were published within the last five years.

Forty-three of the 128 documents in our sample provided definitions of aerosol-generating procedures, as listed in online appendix 5. These documents generally agreed that an aerosol-generating procedure was any intervention or procedure that could produce aerosols capable of transmitting diseases. Some documents specified that these interventions had to involve manipulation of a patient's airway, while others did not. Some documents also specified that aerosol-generating procedures were only those procedures capable of producing aerosols in excess of what is produced when a patient is coughing, breathing or talking, while others made no mention of such a threshold.

The top 10 procedure groups classified as aerosolgenerating, by greatest number of mentions across all included source documents (ie, a frequency count), were: intubation and extubation procedures, airway 
suctioning, bronchoscopy, non-invasive ventilation, nebulised or aerosol therapy, cardiopulmonary resuscitation, sputum induction, tracheostomy and tracheostomy procedures, manual ventilation, and autopsy. These and further procedure groups are presented in online appendix 6 . The likely aerosol sources for the procedures listed as aerosol-generating were assigned by us as follows: tracheobronchial $(n=711$ procedure mentions), inhaled therapy $(n=111)$, oronasal $(n=81)$, autopsy $(n=33)$, wound/invasive procedure $(n=27)$, cleaning tasks $(n=13)$, patient care $(n=13)$, upper gastrointestinal (GI) $(n=5)$, GI-not further specified $(n=2)$, laboratory $(n=2)$ and lower GI $(n=1)$. Online appendix 7 details all mentions of the procedures deemed to be aerosol-generating.

The top 10 procedure groups listed as possibly aerosolgenerating were: chest physiotherapy, nasopharyngeal aspirate, nasopharyngeal and oropharyngeal swabbing, nebulised or aerosol therapy, high-frequency oscillatory ventilation, non-invasive ventilation, tracheostomy and tracheostomy procedures, airway suctioning, coughing, intubation and extubation procedures, and mechanical ventilation. These, further procedure groups, and the associated frequency counts are presented in online appendix 8 . The likely aerosol sources for the possible aerosol-generating procedures were: tracheobronchial $(\mathrm{n}=74$ procedure mentions), oronasal $(\mathrm{n}=26)$, inhaled therapy $(n=17)$, wound/invasive procedure $(n=5)$ and patient care $(n=3)$. Online appendix 9 lists all procedures described as possibly aerosol-generating procedures in the source documents. Online appendices 10 and 11 present data on procedures which were deemed by the source documents to not be aerosol-generating. For these procedures, we assigned no aerosol source.

\section{Ambiguity in procedure classification}

The nature of a given procedure was sometimes ambiguous, making its assignment to a procedure group difficult. This was discussed at length among the authors and led to several iterative refinements of the procedure groups, careful review and sometimes reassignment of procedures to procedure groups.

For example, an Oxylator (a portable ventilator powered by an oxygen cylinder and used in cardiopulmonary resuscitation) may be used with either manual or mechanical ventilation. In such cases, we assigned what we felt was the predominant group; for example, manual ventilation, in the case of the Oxylator.

Another challenge was ambiguous description. This was a common issue in procedures relating to suctioning. Some source documents used the specific term 'airway suctioning', while others listed a procedure as 'suctioning' or 'open suction', without an anatomical location. In some documents, 'open suction' was listed within respiratory physiotherapy interventions, included in a section discussing respiratory droplets, or clearly listed alongside other respiratory procedures (especially intubation, extubation and tracheostomy procedures), allowing us to classify it confidently as 'airway suctioning'. In other documents, the term 'suction' was found in a heterogeneous list (eg, before 'intubation' but after 'autopsy'). In these cases, we could not comfortably assume that 'suction' necessarily meant airway suctioning. Several documents used the term 'suction of body fluids' as a procedure, but we could not find any context clues indicating which body fluids were being suctioned; we therefore grouped those procedures as 'suction of body fluids (not further specified)'. Online appendix 12 details this reasoning further.

The determination of the aerosol source was also sometimes open to interpretation. For example, we assigned an aerosol source of 'oronasal' to the procedure group 'nasopharyngoscopy or laryngoscopy', as we deemed this the most likely source of aerosol. However, if such procedures trigger a cough, then aerosols of 'tracheobronchial' origin would be generated.

\section{Procedure groups with high consensus}

Table 3 lists the 14 procedure groups on which there was very strong (90\% or more) consensus among source documents that the constituent procedures were definitively aerosol-generating or possibly aerosol-generating. It also lists three additional groups of procedures (highfrequency oscillatory ventilation, coughing and mechanical ventilation) for which there was strong $(80 \%$ or more) consensus. As shown in column 3 of table 3, some of these procedures were mentioned in most of the source documents, while others were mentioned less often.

\section{Procedure groups with poor consensus}

Table 4 lists four groups of procedures on which there was less than $80 \%$ consensus. In one of these (oral and dental procedures), consensus was $78 \%$. In the other three (upper GI endoscopy, thoracic surgery and procedures, and nasopharyngeal and oropharyngeal swabbing), there appeared to be substantial disagreement among sources. Possible reasons for disagreement are considered in the Discussion section.

For the controversial procedure groups, one needs to look in more detail; for example, for the oral and dental procedures group, which we recognise is heterogeneous, the procedures deemed to be aerosol-generating often specified the use of a high-speed device, including the use of air turbines, air/water syringes, scopes, high-speed drills, or other power tools or high-speed handpieces; and the use of ultrasonic scalers. Other oral and dental procedures described as aerosol-generating included dental care, dental examinations and the use of propellant anaesthetic freezing sprays such as oral lidocaine.

In contrast, oral and dental procedures labelled as not aerosol-generating did not specify the use of high-speed devices. We found the following procedures listed as not aerosol-generating: dental examinations, oral suctioning or suctioning of the oropharynx, hand scaling with 
Table 3 Procedure groups classified as 'aerosol-generating' or 'possibly aerosol-generating' with high levels of agreement ( $80 \%$ or more of sources)

\begin{tabular}{|c|c|c|c|c|c|}
\hline Procedure group & Aerosol source & $\begin{array}{l}\mathrm{N} \text { of sources } \\
\text { mentioning } \\
\text { procedures in } \\
\text { this group }\end{array}$ & $\begin{array}{l}\mathrm{n}(\%) \text { of sources that } \\
\text { classified procedures } \\
\text { in this group as } \\
\text { aerosol-generating }\end{array}$ & $\begin{array}{l}\mathrm{n}(\%) \text { of sources that } \\
\text { classified procedures in } \\
\text { this group as possibly } \\
\text { aerosol-generating }\end{array}$ & $\begin{array}{l}n(\%) \text { of sources that } \\
\text { classified procedures } \\
\text { in this group as not } \\
\text { aerosol-generating }\end{array}$ \\
\hline Autopsy & Autopsy & 33 & $33(100)$ & $0(0)$ & $0(0)$ \\
\hline $\begin{array}{l}\text { Surgery/postmortem procedures } \\
\text { with high-speed devices }\end{array}$ & $\begin{array}{l}\text { Wound/invasive } \\
\text { procedure }\end{array}$ & 14 & $14(100)$ & $0(0)$ & $0(0)$ \\
\hline $\begin{array}{l}\text { Intubation and extubation } \\
\text { procedures }\end{array}$ & $\begin{array}{l}\text { Tracheobronchial, } \\
\text { oronasal }\end{array}$ & 119 & $114(96)$ & $5(4)$ & $0(0)$ \\
\hline Bronchoscopy & Tracheobronchial & 94 & $89(95)$ & $2(2)$ & $3(3)$ \\
\hline Sputum induction & Tracheobronchial & 64 & $60(94)$ & $2(3)$ & $2(3)$ \\
\hline Manual ventilation & Tracheobronchial & 56 & $52(93)$ & $2(4)$ & $2(4)$ \\
\hline Airway suctioning & $\begin{array}{l}\text { Tracheobronchial, } \\
\text { oronasal }\end{array}$ & 103 & $92(89)$ & $6(6)$ & $5(5)$ \\
\hline Cardiopulmonary resuscitation & Tracheobronchial & 74 & $66(89)$ & $3(4)$ & $5(7)$ \\
\hline $\begin{array}{l}\text { Tracheostomy and tracheostomy } \\
\text { procedures }\end{array}$ & Tracheobronchial & 65 & $57(88)$ & $8(12)$ & $0(0)$ \\
\hline Non-invasive ventilation & Tracheobronchial & 89 & $78(88)$ & $8(9)$ & $3(3)$ \\
\hline High-flow oxygen therapy & Inhaled therapy & 37 & $32(86)$ & $4(11)$ & $1(3)$ \\
\hline $\begin{array}{l}\text { Breaking closed ventilation } \\
\text { systems (intentionally or } \\
\text { unintentionally) }\end{array}$ & Tracheobronchial & 13 & $11(85)$ & $2(15)$ & $0(0)$ \\
\hline Nebulised or aerosol therapy & Inhaled therapy & 91 & 75 (82) & $9(10)$ & $7(8)$ \\
\hline $\begin{array}{l}\text { Nasopharyngoscopy or } \\
\text { laryngoscopy }\end{array}$ & Oronasal & 16 & $12(75)$ & $2(13)$ & $2(13)$ \\
\hline $\begin{array}{l}\text { High-frequency oscillatory } \\
\text { ventilation }\end{array}$ & Tracheobronchial & 39 & $27(69)$ & $9(23)$ & $3(8)$ \\
\hline Coughing & Tracheobronchial & 18 & $10(55)$ & $5(28)$ & $3(17)$ \\
\hline Mechanical ventilation & Tracheobronchial & 15 & $8(53)$ & $4(27)$ & $3(20)$ \\
\hline Chest physiotherapy & Tracheobronchial & 46 & $23(50)$ & $14(30)$ & $9(20)$ \\
\hline Nasopharyngeal aspirate & Oronasal & 29 & $13(45)$ & $12(41)$ & $4(14)$ \\
\hline
\end{tabular}

Percentages were rounded to the nearest full percentage point.

suction, non-surgical extractions, removable denture stages, removal of caries using hand excavation or a slowspeed handpiece, and orogastric tube placement.

\section{Procedure groups with very limited evidence}

Table 5 lists 15 groups of procedures which were each mentioned in fewer than 10 source documents. Some of these (eg, ear, nose and throat and neurosurgery) were classified as aerosol-generating procedures whenever they were mentioned while others (such as nasogastric tube insertion) were classified inconsistently as

Table 4 Procedure groups with high levels of disagreement among sources on aerosol-generating status

\begin{tabular}{|c|c|c|c|c|c|}
\hline Procedure group & Aerosol source & $\begin{array}{l}\mathrm{N} \text { of sources } \\
\text { mentioning } \\
\text { procedures in } \\
\text { this group }\end{array}$ & $\begin{array}{l}\mathbf{n}(\%) \text { of sources } \\
\text { that classified } \\
\text { procedures in this } \\
\text { group as aerosol- } \\
\text { generating }\end{array}$ & $\begin{array}{l}\mathrm{n}(\%) \text { of sources } \\
\text { that classified } \\
\text { procedures in this } \\
\text { group as possibly } \\
\text { aerosol-generating }\end{array}$ & $\begin{array}{l}\mathrm{n}(\%) \text { of sources } \\
\text { that classified } \\
\text { procedures in } \\
\text { this group as not } \\
\text { aerosol-generating }\end{array}$ \\
\hline Oral and dental procedures & Oronasal & 40 & $31(78)$ & $0(0)$ & $9(22)$ \\
\hline $\begin{array}{l}\text { Upper gastrointestinal } \\
\text { endoscopy }\end{array}$ & $\begin{array}{l}\text { Upper } \\
\text { gastrointestinal }\end{array}$ & 10 & $5(50)$ & $2(20)$ & $3(30)$ \\
\hline $\begin{array}{l}\text { Thoracic surgery and } \\
\text { procedures }\end{array}$ & $\begin{array}{l}\text { Wound/invasive } \\
\text { procedure }\end{array}$ & 14 & $4(29)$ & $2(14)$ & $8(57)$ \\
\hline $\begin{array}{l}\text { Nasopharyngeal and } \\
\text { oropharyngeal swabbing }\end{array}$ & Oronasal & 34 & $9(27)$ & $10(29)$ & $15(44)$ \\
\hline
\end{tabular}

Percentages were rounded to the nearest full percentage point. 
Table 5 Procedure groups with limited evidence ( $<10$ sources)

\begin{tabular}{|c|c|c|c|c|c|}
\hline Procedure group & $\begin{array}{l}\text { Aerosol source } \\
\text { (if procedures aerosol- } \\
\text { generating or possibly } \\
\text { aerosol-generating) }\end{array}$ & $\begin{array}{l}\mathrm{N} \text { of sources } \\
\text { mentioning } \\
\text { procedures in } \\
\text { this group }\end{array}$ & $\begin{array}{l}\mathrm{n}(\%) \text { of sources } \\
\text { that classified } \\
\text { procedures in this } \\
\text { group as aerosol- } \\
\text { generating }\end{array}$ & $\begin{array}{l}\mathrm{n}(\%) \text { of sources } \\
\text { that classified } \\
\text { procedures in this } \\
\text { group as possibly } \\
\text { aerosol-generating }\end{array}$ & $\begin{array}{l}\mathrm{n}(\%) \text { of sources } \\
\text { that classified } \\
\text { procedures in } \\
\text { this group as not } \\
\text { aerosol-generating }\end{array}$ \\
\hline ENT and neurosurgery & $\begin{array}{l}\text { Wound/invasive } \\
\text { procedure }\end{array}$ & 3 & $3(100)$ & $0(0)$ & $0(0)$ \\
\hline $\begin{array}{l}\text { Gl endoscopy (not further } \\
\text { specified) }\end{array}$ & GI (not further specified) & 2 & $2(100)$ & $0(0)$ & $0(0)$ \\
\hline $\begin{array}{l}\text { Intra/extra pulmonary high- } \\
\text { frequency oscillation devices }\end{array}$ & Tracheobronchial & 3 & $2(67)$ & $1(33)$ & $0(0)$ \\
\hline Toilet use and flushing & Cleaning tasks & 2 & $2(100)$ & $0(0)$ & $0(0)$ \\
\hline Vacuum cleaning & Cleaning tasks & 2 & $2(100)$ & $0(0)$ & $0(0)$ \\
\hline Supraglottic airways & Tracheobronchial & 1 & $1(100)$ & $0(0)$ & $0(0)$ \\
\hline Manipulation of masks & Oronasal & 8 & $5(63)$ & $0(0)$ & $3(37)$ \\
\hline Lung function testing & Tracheobronchial & 7 & $4(57)$ & $2(29)$ & $1(14)$ \\
\hline $\begin{array}{l}\text { Suction of body fluids (not } \\
\text { further specified) }\end{array}$ & Patient care & 6 & $3(50)$ & $2(33)$ & $1(17)$ \\
\hline Colonoscopy & Lower GI & 2 & $1(50)$ & $0(0)$ & $1(50)$ \\
\hline Nasogastric tube insertion & Oronasal & 9 & $4(44)$ & $1(11)$ & $4(44)$ \\
\hline $\begin{array}{l}\text { Nitrous oxide (Entonox) } \\
\text { administration }\end{array}$ & - & 2 & $0(0)$ & $0(0)$ & $2(100)$ \\
\hline Labour and delivery & - & 1 & $0(0)$ & $0(0)$ & $1(100)$ \\
\hline
\end{tabular}

Percentages were rounded to the nearest full percentage point. Totals may therefore not equal $100 \%$ exactly.

ENT, ear, nose and throat; GI, gastrointestinal.

aerosol-generating, possibly aerosol-generating or not aerosol-generating. However, the small number of source documents for these procedure groups means that no firm conclusions can be drawn.

\section{DISCUSSION}

This rapid systematic review has produced a number of key findings. First, we have reduced a lengthy list of procedures to 39 procedure groups, making the classification of such procedures easier. We have also developed a taxonomy of the likely sources of aerosols.

Second, we believe we have identified a substantial body of relevant literature and that this has allowed us to draw reasonably confident conclusions as to which procedures have been most frequently identified as being aerosol-generating.

Third, through a thorough search and synthesis of this literature, we have identified a number of procedures on which there is already high consensus that these are aerosol-generating or possibly aerosol-generating. In view of the seriousness of COVID-19 and the known occupational risk to healthcare workers, we recommend that the procedures listed in table 3 be treated as aerosolgenerating procedures for the purposes of selecting personal protective equipment.
Fourth, we have identified a list of potential aerosolgenerating procedures on which guidance appears to be sparse. Of particular note is the fact that certain very common procedures (such as colonoscopy and procedures relating to labour and delivery) were barely mentioned in our sample of 128 documents. It is possible that our search missed specialist publications, so a logical next step would be more specific searches for these procedures. If dependable literature addressing these cannot be identified, we recommend that professional and regulatory bodies note the list of procedures presented in table 4 and hold meetings to establish the current level of multidisciplinary professional consensus.

Finally, we have identified a small number of procedures (shown in table 4) on which there appears to be substantial disagreement. The groups 'oral and dental procedures' and 'thoracic surgery and procedures' were broad and each covered a range of procedures. Upper GI endoscopy was covered by only 10 documents, so more specific searching and arriving at expert consensus may be indicated for this procedure group, too. For the other contested procedure group (nasopharyngeal and oropharyngeal swabbing), we recommend that a process of achieving expert consensus be used, such as a modified Delphi method among a panel of relevant 
experts who examine each of our 34 sources individually, ideally supplemented by an updated literature search. ${ }^{21}$ Strengths of our paper include an extensive literature search, yielding a dataset that covers both academic and grey literature and also a very wide range of settings, authorities and jurisdictions. Furthermore, all data were at least double-checked. We believe this is the first systematic, international survey of guidance on aerosolgenerating procedures.

This study has a number of limitations. The chief limitation is that we were working from secondary sources and were not resourced to go back to primary evidence on which recommendations would have been based. While we can have some confidence in widespread agreement among experts that a procedure is aerosol-generating, the reverse is not necessarily true. It is possible that procedures not listed in guidance documents as aerosolgenerating may still produce aerosols, especially when those procedures are relatively new or where there has been no specific research to confirm or refute the hypothesis. The list in table 3 should therefore not be viewed as exhaustive.

Additionally, we could have categorised the various, slightly differing, descriptions of procedures that we found in the included source documents in a number of ways. While the procedure groups and aerosol sources described in our review represent the consensus of a diverse set of authors with expertise in the subject matter, in evidence synthesis methodology, and in medical taxonomy, our groupings are, in a sense, arbitrary and various different schemata may be equally valid.

Moreover, the frequency counting approach is at best an approximation of expert consensus; we counted each mention equally, but perhaps should not have. The documents we included were addressed to different audiences, developed with varying degrees of scholarly rigour, and they were sometimes based on one another or based on common sources.

We did not undertake a formal risk of bias assessment of our included documents, partly because no suitable tool could be identified and partly because our objective was to map the variation in recommendations across the full range of official guidance.

As noted above, some clinically relevant procedures received surprisingly little mention in our source documents. We therefore cannot conclude that our search, extensive as it was, led to a classification of aerosolgenerating procedures that is complete for all clinical situations. In particular, colonoscopy as well as labour and delivery procedures will clearly require further exploration. There were other infrequently mentioned procedures which are performed in healthcare settings but are not medical in nature, such as vacuum cleaning and toilet flushing; these may nonetheless be relevant and would also require further specific attention.

The reader will also note that we found more Canadian resources than one might expect from Canada's share of the global economy and population. Likely, we fell victim to a degree of 'home country bias'-we searched globally, but our familiarity with Canadian resources may have meant that we have identified those more readily than others. We caution the reader to consider this, but at the same time want to propose that Canada can serve as a model Western society and that the considerations of Canadian health services are also applicable elsewhere.

A number of findings from this review prompt new hypotheses that should be taken forward. One theme that emerged, for example, is that various procedures deemed to be aerosol-generating were suggested to have the potential to trigger coughing, and coughing in itself was characterised as aerosol-generating in multiple source documents. For such procedures, triggering a cough might therefore be the mode of aerosol generation.

In this context, it is worth noting that coughing can aerosolise viruses. Jones and Brosseau proposed a model for evaluating the quality of evidence for aerosol transmission of an infectious disease, with three conditions: aerosol generation (containing pathogens), environmental viability, and access to target tissue (resulting in infection). ${ }^{22}$ They found that there was strong evidence for aerosol transmission of influenza and severe acute respiratory syndrome (SARS), among other diseases. We can therefore draw from the literature on influenza and SARS with some confidence of its generalisability. There is specific evidence that influenza may be transmitted by coughing, which Huynh et al found to produce airborne particles containing viable virus; these particles can then be inhaled by others, especially in close proximity. ${ }^{23}$ Lindsley et al examined exposure from coughing using breathing and coughing simulators and found that the breathing simulator would incur substantial exposure at a distance of $46 \mathrm{~cm}$ from the coughing simulator, but that distancing to $183 \mathrm{~cm}$ could reduce exposure by $92 \% .^{24}$ However, another study using the same methodology demonstrated that cough particles spread throughout a room within several minutes, meaning anyone in the room may be exposed regardless of their location. ${ }^{6}$

Recent work in fluid dynamics has suggested that longstanding assumptions about how aerosols are generated, that is, that coughs produce aerosolised particles of respiratory secretions expelled in a direct trajectory, may underestimate the exposure risk. We now know that coughs and sneezes are primarily composed of turbulent gas clouds which contains droplets of various sizes, and which can travel 7-8 m. ${ }^{7}$ Van Doremalen et al investigated the aerosol and surface stability of SARS-CoV-2 and compared it with SARS-CoV (the virus that causes SARS), finding them similar, supportive of aerosol and fomite transmission. ${ }^{5}$

If any procedure that triggers coughing is potentially associated with the generation of aerosols, the implications for personal protective equipment during the COVID-19 pandemic are profound, especially since coughing is a common symptom of COVID-19. ${ }^{17}$ A study assessing the efficacy of different protective equipment showed that N95 respirators were effective protection 
against aerosol exposure from a close-range cough, while surgical masks were inadequate. ${ }^{12}$ Other laboratory studies have shown similar findings, notably that highergrade personal protective equipment (N95 respirators) worn by both patients and healthcare workers reduced exposure to such particles. ${ }^{5}$

While the debate about aerosol-generating procedures in the context of COVID-19 has focused primarily on the question of when and how healthcare workers should select respirators, there are many other measures that should be taken to reduce viral transmission when undertaking a healthcare procedure or exposure that could generate aerosols. Systems-level modifications to facilities include optimising air ventilation and decreasing relative humidity. ${ }^{25}$ Experiments with aerosolised SARS-CoV-2 in artificial saliva have shown it to be twice as stable as influenza at medium humidity $(40 \%-60 \%)$, and to have longer viability in high humidity $(68 \%-88 \%)$ compared with lower humidities. ${ }^{26}$ Interventions clinicians can undertake personally include self-distancing (eg, from a coughing patient) and careful doffing of personal protective equipment. Consideration should also be given to continuous masking by staff and patients. ${ }^{27}$

In conclusion, this rapid systematic review has added to the evidence base for the classification of aerosolgenerating procedures. While the literature has many gaps, we believe that there is sufficient evidence to confidently classify at least 19 procedure groups as aerosolgenerating. To reduce dissent on the remainder, we recommend that (a) clinicians define procedures more clearly and specifically, breaking them down into their constituent components where possible; (b) researchers undertake further studies of aerosolisation during these procedures; and (c) guideline-making and policy-making bodies address a wider range of procedures.

\section{Author affiliations}

${ }^{1}$ Division of Preventive Medicine, Department of Medicine, University of Alberta, Edmonton, Alberta, Canada

${ }^{2}$ Division of Occupational Medicine, Department of Medicine, University of Toronto, Toronto, Ontario, Canada

${ }^{3}$ Diabetes Research Centre, University of Leicester, Leicester, UK

${ }^{4}$ School of Medicine and Dentistry, Barts and the London School of Medicine and Dentistry, London, UK

${ }^{5}$ Canadian Standards Biological Aerosols Group, Canadian Standards

Association, Toronto, Ontario, Canada

${ }^{6}$ Centre for Tropical Medicine and Global Health, Nuffield Department of Medicine, University of Oxford, Oxford, UK

${ }^{7}$ Division of Infectious Diseases, Children's Hospital of Los Angeles, Los Angeles, California, USA

${ }^{8}$ Bodleian Health Care Libraries, University of Oxford, Oxford, UK

${ }^{9}$ School of Allied Health, University of Limerick, Limerick, Ireland

${ }^{10}$ Nuffield Department of Primary Care Health Sciences, University of Oxford,

Oxford, Oxfordshire, UK

${ }^{11}$ Medical Sciences Division, University of Oxford, Oxford, UK

Acknowledgements We gratefully acknowledge Dr. Jinghui Chen for help with classifying the procedures.

Contributors TJ contributed to searching, data extraction and data management, performed calculations, wrote manuscript text and managed references. DD contributed to searching and data extraction, classified procedures, performed calculations and wrote manuscript text. GW contributed to searching, data extraction and data management, wrote manuscript text and managed references. QD-M contributed to searching and data extraction. AA adjudicated differences in data extraction and classified procedures. KK, SK and SSm wrote manuscript text and contributed references. XHSC and LR classified procedures. NR contributed to searching. ET contributed to searching and data extraction. TG performed calculations and wrote manuscript text. IA, SMB, JD, NS and RT verified the data extraction. SSt conceived and directed the systematic review, extracted data, classified procedures and wrote manuscript text. All authors reviewed the manuscript and approved the final version before submission.

Funding Research support to Professor Straube at the University of Alberta was provided by a grant from the Workers' Compensation Board of Alberta, 'Program of Research and Training in Occupational Medicine', which was used to employ Dr Jackson, Ms Deibert and Mr Wyatt for work on this project as well as to pay for the publication fee for this article. Professor Greenhalgh's work is supported by UK National Institute for Health Research (BRC-1215-20008), UK Research and Innovation (COVID-19 Emergency Fund) and Wellcome Trust (WT104830MA). Professor Khunti is supported by the National Institute for Health Research (NIHR) Applied Research Collaboration East Midlands (ARC EM) and the NIHR Leicester Biomedical Research Centre (BRC). The views expressed are those of the authors and not necessarily those of any funders.

Disclaimer SSt is the manuscript's guarantor and affirms that the manuscript is an honest, accurate and transparent account of the study being reported; that no important aspects of the study have been omitted and that any discrepancies from the study as planned (and, if relevant, registered) have been explained.

Competing interests QD-M reports grants from the Workers' Compensation Board of Alberta, during the conduct of the study. SSm reports other from 3M Canada Company, outside the submitted work. In addition, SSm has a patent $P$. Legare, G.E. Dwyer, A. Murphy, S.J. Smith 'Air filtration device' US Patent 9.744.493 and European Patent 2274067 (2008). issued, and a patent R.A. Abdulqader, S.C. Dodds, A.M. Gilman, A.D. Groth, C.P. Henderson, D.M. Maanum, L.V. Palaikis, N.A. Rakow, S.J. Smith, E. Evgeny, 'Filtering face-piece respirator including functional material and method of forming same' World Patent 201766284 (2015). issued. SSt reports grants from the Workers' Compensation Board of Alberta during the conduct of the study; personal fees from the Workers' Compensation Board of Alberta, personal fees from WorkSafeBC and personal fees from the Canadian Board of Occupational Medicine, outside the submitted work.

Patient and public involvement Patients and/or the public were not involved in the design, or conduct, or reporting, or dissemination plans of this research.

Patient consent for publication Not required.

Provenance and peer review Not commissioned; externally peer reviewed.

Data availability statement Data are available upon reasonable request. Much of the data is uploaded as a supplement. Those wishing additional raw data may contact Professor Straube.

Open access This is an open access article distributed in accordance with the Creative Commons Attribution Non Commercial (CC BY-NC 4.0) license, which permits others to distribute, remix, adapt, build upon this work non-commercially, and license their derivative works on different terms, provided the original work is properly cited, appropriate credit is given, any changes made indicated, and the use is non-commercial. See: http://creativecommons.org/licenses/by-nc/4.0/.

ORCID iDs

Tanya Jackson http://orcid.org/0000-0002-8159-7421

Anil Adisesh http://orcid.org/0000-0002-4973-8474

Xin Hui S Chan http://orcid.org/0000-0002-9941-6975

Sebastian Straube http://orcid.org/0000-0001-7862-0398

\section{REFERENCES}

1 Bake B, Larsson P, Ljungkvist G, et al. Exhaled particles and small airways. Respir Res 2019;20:8.

2 Lindsley WG, Pearce TA, Hudnall JB, et al. Quantity and size distribution of cough-generated aerosol particles produced by influenza patients during and after illness. J Occup Environ Hyg 2012;9:443-9.

3 Pirtle EC, Beran GW. Virus survival in the environment. Rev Sci Tech 1991;10:733-48.

4 Cimolai N. Environmental and decontamination issues for human coronaviruses and their potential surrogates. J Med Virol 2020. doi:10.1002/jmv.26170. [Epub ahead of print: 12 Jun 2020].

5 van Doremalen N, Bushmaker T, Morris DH, et al. Aerosol and surface stability of SARS-CoV-2 as compared with SARS-CoV-1. N Engl J Med 2020;382:1564-7. 
6 Lindsley WG, King WP, Thewlis RE, et al. Dispersion and exposure to a cough-generated aerosol in a simulated medical examination room. J Occup Environ Hyg 2012:9:681-90.

7 Bourouiba L. Turbulent gas clouds and respiratory pathogen emissions: potential implications for reducing transmission of COVID-19. JAMA 2020;323:1837-8.

8 Papineni RS, Rosenthal FS. The size distribution of droplets in the exhaled breath of healthy human subjects. J Aerosol Med 1997:10:105-16.

9 Li Y, Leung GM, Tang JW, et al. Role of ventilation in airborne transmission of infectious agents in the built environment - a multidisciplinary systematic review. Indoor Air 2007;17:2-18.

10 McDermott CV, Alicic RZ, Harden N, et al. Put a lid on it: are faecal bio-aerosols a route of transmission for SARS-CoV-2? J Hosp Infect 2020;105:397-8

11 Knowlton SD, Boles CL, Perencevich EN, et al. Bioaerosol concentrations generated from toilet flushing in a hospital-based patient care setting. Antimicrob Resist Infect Control 2018;7:16.

12 World Health Organization. Infection prevention and control during health care when COVID-19 is suspected: interim guidance, 2020 Available: https://apps.who.int/iris/bitstream/handle/10665/331495/ WHO-2019-nCoV-IPC-2020.3-eng.pdf [Accessed 28 Sep 2020].

13 Duguid JP. The size and the duration of air-carriage of respiratory droplets and droplet-nuclei. J Hyg 1946;44:471-9.

14 Liu Y, Ning Z, Chen Y, et al. Aerodynamic analysis of SARS-CoV-2 in two Wuhan hospitals. Nature 2020;582:557-60.

15 Jamieson DJ, Steinberg JP, Martinello RA, et al. Obstetricians on the coronavirus disease 2019 (COVID-19) front lines and the confusing world of personal protective equipment. Obstet Gynecol 2020;135:1257-63.

16 Evanoff BA, Strickland JR, Dale AM, et al. Work-Related and personal factors associated with mental well-being during the COVID-19 response: survey of health care and other workers. J Med Internet Res 2020;22:e21366.

17 Zhang J, Zhang L, Yin Y, et al. Best practice for infection prevention in pediatric respiratory clinics during the COVID-19 epidemic. World $J$ Pediatr 2020:1-7.
18 Centers for Disease Control and Prevention. Interim infection prevention and control recommendations for healthcare personnel during the coronavirus disease 2019 (COVID-19) pandemic, 2019. Available: https://www.cdc.gov/coronavirus/2019-ncov/hcp/ infection-control-recommendations.html [Accessed 4 Jul 2020].

19 Garritty C, Gartlehner G, Kamel C, et al. Cochrane rapid reviews interim guidance from the Cochrane rapid reviews methods group, 2020. Available: https://methods.cochrane.org/rapidreviews/sites/ methods.cochrane.org.rapidreviews/files/public/uploads/cochrane rr_-_guidance-23mar2020-v1.pdf

20 Moher D, Liberati A, Tetzlaff J, et al. Preferred reporting items for systematic reviews and meta-analyses: the PRISMA statement. PLOS Med 2009;6:e1000097.

21 Eubank BH, Mohtadi NG, Lafave MR, et al. Using the modified Delphi method to establish clinical consensus for the diagnosis and treatment of patients with rotator cuff pathology. BMC Med Res Methodol 2016;16:56.

22 Jones RM, Brosseau LM. Aerosol transmission of infectious disease. J Occup Environ Med 2015;57:501-8.

23 Huynh KN, Oliver BG, Stelzer S, et al. A new method for sampling and detection of exhaled respiratory virus aerosols. Clin Infect Dis 2008;46:93-5.

24 Lindsley WG, Noti JD, Blachere FM, et al. Efficacy of face shields against cough aerosol droplets from a cough simulator. $J$ Occup Environ Hyg 2014;11:509-18.

25 Kumar P, Morawska L. Could fighting airborne transmission be the next line of defence against COVID-19 spread? City and Environment Interactions 2019;4:100033.

26 Smither SJ, Eastaugh LS, Findlay JS, et al. Experimental aerosol survival of SARS-CoV-2 in artificial saliva and tissue culture media at medium and high humidity. Emerg Microbes Infect 2020:9:1415-7.

27 World Health Organization (WHO). Advice on the use of masks in the context of COVID-19: interim guidance, 2020. Available: https:// apps.who.int/iris/handle/10665/332293 